\title{
Logistics Industry Efficiency and Its Determinants in Silk Road Economic Belt Core Area Xinjiang
}

\author{
Juan Li and Liyi Zhao \\ Shaanxi Institute of International Trade \& Commerce, Xi'an Shaanxi, China
}

\begin{abstract}
Based on a clear definition of the core concepts, the article first applies the DEA Model to recieve logistics industry efficiency in Xinjiang, which is located in Silk Road Economic Belt Core Area, from 2003 to 2015 in terms of comprehensive efficiency, economies of Scale and Pure Technical Efficiency Empirical analysis; Then using Tobit Regression Model and Stepwise Regression Model, using Eviews8.0 software to analyze the factors affecting logistics industry efficiency in Xinjiang. The results show that the comprehensive logistics industry efficiency in Xinjiang is high, but the average of three kinds of efficiency is less than 1, which means there is still much room for improvement in the three efficiency values of logistics industry in Xinjiang. The three core factors affecting logistics industry efficiency in Xinjiang are the level of opening up, Industrial structure and logistics practitioners. Therefore, we should further improve logistics industry efficiency in Xinjiang from three aspects such as making full use of the opening up of the Belt and Road Initiative, promoting the optimization and upgrading of the industrial structure, and enhancing the number and professionalism of the logistics practitioners.
\end{abstract}

\section{Introduction}

Xinjiang (Xinjiang Uygur Autonomous Region) is the largest provincial administrative region in China. It is located in the hinterland of Asia-Europe, and borders with Russia, Kazakhstan and other eight countries. It is an important passage for the ancient Silk Road. On March 28, 2015, the "National Development and Reform Commission and other "Vision and Action for Promoting the Construction of the Silk Road Economic Belt and the 21st Century Maritime Silk Road" defined Xinjiang as the core area of the Silk Road Economic Belt. Studying the efficiency of Xinjiang logistics industry and its influencing factors can not only accurately locate the efficiency level of Xinjiang logistics industry and evaluate its influencing factors, but also have important significance for promoting the overall development level of Silk Road Economic Belt.

The literature found that there is little literature on the overall evaluation of the efficiency of Xinjiang logistics industry in the core area of the Silk Road Economic Belt, and an empirical study on the factors affecting the efficiency of Xinjiang logistics industry. Based on this, based on the theoretical analysis of the logistics industry efficiency, the article selects the evaluation index, uses the DEA model to evaluate the efficiency of the logistics industry in Xinjiang from 2003 to 2015, and then uses the Tobit model and the stepwise regression model to influence the influencing factors. Analysis on the impact of logistics industry efficiency. Finally, based on the analysis results, the policy recommendations for promoting the development of the logistics industry in the core area of the Silk Road were proposed.

\section{Evaluation of Xinjiang logistics industry efficiency based on DEA model}

\subsection{Research methods}

This paper chooses to use the DEA method. The common models of DEA are divided into CCR model and BCC model. The CCR model can measure the overall technical efficiency of the decision-making unit, and the BCC model measures the pure technical efficiency.

\subsection{Selection of evaluation indicators and data sources}

\subsubsection{Evaluation index selection}

Based on the views of previous scholars ${ }^{[1-2]}$, the representativeness of indicators, and the availability of data, this paper chooses the logistics industry efficiency index system:

Input indicator: (1) Employees in the logistics industry (choose workers in the transportation, warehousing and postal service industries); (2) The fixed assets investment of the logistics industry (choose the total investment in fixed assets of the transportation, warehousing and postal services industries); (3) Length 
of road line (select the mileage of the grade road instead).

Output indicator: (1) Logistics industry output value;

(2) Total transportation volume; (3) Cargo turnover.

\subsubsection{Data source}

The data in this paper is from the China Statistical Yearbook 2004-2016.

\subsection{Empirical results and evaluation}

Based on the construction of Xinjiang logistics industry efficiency input and output index system, DEA solver 5.0 software is used to measure the efficiency of logistics industry in Xinjiang from 2003 to 2015. The results are as follows:

Table 1. Logistics industry efficiency in Xinjiang from 2003 to 2015.

\begin{tabular}{|c|c|c|c|}
\hline DMU & $\begin{array}{c}\text { Overall Technical } \\
\text { Efficiency }\end{array}$ & $\begin{array}{c}\text { Pure Technical } \\
\text { Efficiency }\end{array}$ & $\begin{array}{c}\text { Scale } \\
\text { Efficiency }\end{array}$ \\
\hline 2003 & 1 & 1 & 1 \\
\hline 2004 & 1 & 1 & 1 \\
\hline 2005 & 0.9611 & 1 & 0.9611 \\
\hline 2006 & 0.883 & 0.9784 & 0.9024 \\
\hline 2007 & 1 & 1 & 1 \\
\hline 2008 & 1 & 1 & 1 \\
\hline 2009 & 0.9462 & 0.9766 & 0.9689 \\
\hline 2010 & 0.9917 & 0.9919 & 0.9999 \\
\hline 2011 & 1 & 1 & 1 \\
\hline 2012 & 1 & 1 & 1 \\
\hline 2013 & 1 & 1 & 1 \\
\hline 2014 & 1 & 1 & 1 \\
\hline 2015 & 1 & 1 & 1 \\
\hline Mean & 0.9832 & 0.9959 & 0.9871 \\
\hline
\end{tabular}

It can be seen from Table 1: (1) The comprehensive logistics efficiency of Xinjiang in 2003, 2004, 2007, 2008 and 2011-2015 is 1 , which is valid for DEA, indicating that the logistics industry in Xinjiang is more efficient in the past 9 years. High, the logistics resources of Xinjiang logistics industry are reasonable. (2) The comprehensive logistics efficiency in 2005, 2006, 2009 and 2010 is less than 1 , which means that the DEA is invalid, indicating that the logistics industry in Xinjiang has been inefficient for the past four years. (3) Integrating the efficiency of the logistics industry from 2003 to 2015 , we can see that the average efficiency of the logistics industry in Xinjiang is 0.9832 , the average technical efficiency is 0.9959 , the average efficiency of scale is 0.9871 , and the overall scale of returns is in the non-reduction phase. The efficiency of the logistics industry in Xinjiang is generally high. However, the three efficiency values are all less than 1, indicating that Xinjiang logistics industry has room for improvement in overall efficiency, pure technical efficiency and scale efficiency.

\section{Regression analysis between logistics industry efficiency and its influencing factors in Xinjiang}

\subsection{Influencing factors}

The efficiency of the logistics industry is affected by many factors. Based on the previous studies, this paper combines the actual situation of Xinjiang, mainly to examine the level of economic development, industrial structure, logistics infrastructure, logistics practitioners, marketization, openness and technological progress. And the impact of information technology on the efficiency of the logistics industry.

\subsection{Research methods}

The Tobit model is used to analyze the factors affecting the efficiency of Xinjiang logistics industry. The Tobit regression model is established as follows:

$$
\begin{aligned}
\mathrm{Y}_{\mathrm{i}}=\beta_{0}+\beta_{1} \mathrm{GDP}_{\mathrm{i}} & +\beta_{2} \text { INDUS }_{\mathrm{i}}+\beta_{3} \text { INFRAS }_{\mathrm{i}}+\beta_{4} \text { EMPL }_{\mathrm{i}} \\
& +\beta_{5} \text { MARK }_{\mathrm{i}}+\beta_{6} \text { OPEN }_{\mathrm{i}}+\beta_{7} \text { INFRO }_{\mathrm{i}} \\
& +\mu
\end{aligned}
$$

$\mathrm{Yi}$ represents the efficiency of the i-phase logistics industry, that is, the comprehensive efficiency value, the value range is $[0,1] ; \beta_{0}$ is a constant term, $\beta 1, \beta 2, \beta 3, \beta 4$, $\beta 5, \beta 6$ and $\beta 7$ are regression coefficients; GDP represents GDP value; INDUS represents industrial structure; INFRAS represents logistics industry infrastructure; EMPL represents the number of employees logistics industry; MARK represents the marketization level of Xinjiang; OPEN represents the degree of opening; INFRO represents information level, and $\mu$ is the random error term.

The data comes from the WIND database and the China Statistical Yearbook.

\subsection{Analysis and evaluation of empirical results}

Using Eviews 8.0 Software to analyze the data, the results are as follows:

Table 2. Tobit model regression results.

\begin{tabular}{|c|c|c|c|c|}
\hline Variable & Coefficient & Std.Error & Z-Statistic & Prob. \\
\hline con_S & 0.9642 & 0.1185 & 8.1348 & $0.0000 * * *$ \\
\hline GDP & $-4.51 \mathrm{E}-05$ & $3.09 \mathrm{E}-05$ & -1.4570 & 0.1451 \\
\hline INDUS & 0.8024 & 0.7011 & 1.1445 & $0.0225 * *$ \\
\hline INFRAS & 0.0002 & 0.0002 & 1.0895 & 0.2759 \\
\hline EMPL & 0.0110 & 0.0047 & 2.3453 & $0.0290 * *$ \\
\hline MARK & -0.0197 & 0.0143 & -1.3713 & 0.1703 \\
\hline OPEN & 0.9037 & 0.9567 & 0.9446 & $0.0158 * *$ \\
\hline INFRO & $3.35 \mathrm{E}-06$ & $5.54 \mathrm{E}-05$ & 0.0605 & 0.9518 \\
\hline
\end{tabular}

*represents a significant level of $10 \%, * *$ represents a significant level of $5 \%$, and $* * *$ represents a significant level of $1 \%$

It can be seen from Table 2 that (1) according to the degree of influence on the efficiency of the logistics industry, the influencing factors can be ranked as: the degree of openness - the industrial structure - the employees of the logistics industry - the level of economic development - the degree of marketization - the infrastructure of the logistics industry - Technological progress and the degree of informatization. (2) Analysis 
of insignificant factors: The correlation coefficients of Xinjiang logistics industry efficiency and economic development level, marketization degree, logistics industry infrastructure, technological progress and informatization degree are: $0.37,0.38,0.29,0.05$ respectively. It shows that these factors have a certain correlation with the efficiency of the logistics industry, but because of the data selection interval, the impact of these variables on the efficiency of the logistics industry is not statistically significant. This paper further adopts Tobit and stepwise regression model to obtain the factors that have a significant impact on the efficiency of Xinjiang logistics industry.

Firstly, the Tobit model is used to regress the GDP of the first explanatory variable, and gradually increase the number of explanatory variables. For each regression, the model is subjected to F test, t-test is performed on the explanatory variables, and then the insignificant variables are gradually eliminated. This process is repeated. Six times, until there are no inconspicuous explanatory variables in the model, at this time, the results are optimal. After repeated operations, the stepwise regression results are shown in the following table:

Table 3. Stepwise regression results.

\begin{tabular}{|c|c|c|c|c|}
\hline Variable & Coefficient & Std.Error & Z-Statistic & Prob. \\
\hline con_S & 0.8287 & 0.0662 & 12.5096 & $0.0000 * * *$ \\
\hline INDUS & 0.9028 & 0.9012 & 1.0018 & $0.0197 * *$ \\
\hline EMPL & 0.0161 & 0.0073 & 2.2089 & $0.0272 * *$ \\
\hline OPEN & 0.9166 & 0.9409 & 0.9741 & $0.0160 * *$ \\
\hline
\end{tabular}

*represents a significant level of $10 \%$, **represents a significant level of $5 \%$, and ***represents a significant level of $1 \%$

It can be seen from Table 3 that: (1) the level of opening up is under 5\% significant level, industrial structure and marketization are the top three significant factors affecting the efficiency of Xinjiang's logistics industry. (2) The degree of openness is positively correlated with the efficiency of the logistics industry, with a coefficient of 0.9166, indicating that the improvement of the degree of openness plays a key role in improving the efficiency of the logistics industry in Xinjiang. (3) The industrial structure is highly correlated with the efficiency of the logistics industry. The coefficient is 0.9028 , indicating the adjustment of the industrial structure. The growth of the tertiary industry's output value has a significant effect on the efficiency of the logistics industry. (4) The number of logistics employees is positively correlated with the efficiency of the logistics industry, with a coefficient of 0.0161 , indicating that the increase in the number of logistics employees in Xinjiang can effectively improve the efficiency of the logistics industry during 2003-2015.

\section{Summary and policy recommendations}

This paper selects the DEA model and uses DEA solver 5.0 Software to evaluate logistics industry efficiency in Xinjiang from 2003 to 2015. It is found that the efficiency of Xinjiang integrated logistics industry is generally higher, but the three efficiency values are less than 1, indicating the comprehensive efficiency of Xinjiang logistics industry. Pure technical efficiency and scale efficiency have room for improvement. Then using Tobit model and stepwise regression model, using Eviews8.0 software to analyze the influencing factors of logistics efficiency in Xinjiang from 2003 to 2015, it is found that the three most influential factors of Xinjiang logistics industry are the degree of openness and industry. Number of structural and logistics practitioners.

Based on the results of empirical analysis, this paper proposes the following policy recommendations:

(1) Xinjiang should actively use the opportunity of the national "Belt and Road" development strategy to actively play its role in the core area of the Silk Road Economic Belt and enhance its level of opening up.

(2) Xinjiang should be a "big" and a "strong" tertiary industry to promote the optimization and upgrading of industrial structure.

(3) Enhance the professionalism of the employees in the logistics industry, and strengthen the professional, technical and service level training for logistics practitioners.

\section{References}

1. Weber C A. A data envelopment analysis approach to measuring vendor performance (Supply Chain Management, An International Journal, 1996).

2. Wang Qinmei, Tan Cuiwei. An Empirical Study on the Efficiency of Xi'an Logistics Industry and Its Influencing Factors (Soft Science, 2013). 